Jurnal Kesehatan Hesti Wira Sakti

ISSN 2302-4283 (print)

ISSN 2580-9571 (online)

Online di https://jurnal.poltekkes-soepraoen.ac.id

DOI: $10.47794 / \mathrm{jkhws.v8i2}$

\title{
GAMBARAN PELAKSANAAN STANDAR PELAYANAN KEFARMASIAN DI APOTEK ARJASA KOTA MALANG
}

\author{
Mayang Aditya Ayuning Siwi ${ }^{1}$ \\ ${ }^{1}$ Program Studi DIII Farmasi, ITSK RS dr. Soepraoen \\ (Korespondensi: adityamayang51@gmail.com )
}

\begin{abstract}
ABSTRAK
Pendahuluan Standar pelayanan kefarmasian di apotek merupakan dasar dalam pelayanan di apotek dan sebagai tolok ukur yang digunakan sebagai pedoman bagi tenaga kefarmasian dalam menyelenggarakan pelayanan kefarmasian. Penelitian ini bertujuan untuk mengetahui kesesuaian pelaksanaan standar pelayanan kefarmasian di apotek berdasarkan Permenkes No.73 tahun 2016 di apotek Arjasa Malang. Metode Penelitian ini merupakan penelitian non eksperimental dengan jenis penelitian deskriptif. Sampel pada penelitian ini adalah apoteker pengelola apotek sebanyak 2 apoteker yang bersedia menjadi responden. Pengumpulan data dilakukan dengan menggunakan kuesioner yang berisi 39 pernyataan. Hasil Berdasarkan hasil penelitian yang telah dilakukan adalah Apotek Arjasa 1 dan 2 adalah apotek yang dimiliki oleh apotekernya sendiri sehingga pelaksanaan standard pelayanan kefarmasian hamper seluruhnya sudah dilakukan. Kesimpulan dari penelitian ini adalah didapatkan persentase kesesuaian pelaksanaan pelayanan kefarmasian di Apotek Arjasa 1 dan 2 dengan Permenkes No. 73 tahun 2016 adalah sebesar 95,24\% untuk bidang pengelolaan sediaan kefarmasian dan sebesar $100 \%$ untuk pelayanan farmasi klinik.
\end{abstract}

Kata kunci: Apotek Arjasa, Permenkes No. 73 Tahun 2016, Standar Pelayanan Kefarmasian

\begin{abstract}
Introduction Pharmaceutical service standards in pharmacies are the basis for services in pharmacies and as benchmarks that are used as guidelines for pharmaceutical personnel in carrying out pharmaceutical services. This study aims to determine the suitability of the implementation of pharmaceutical service standards in pharmacies based on Permenkes No.73 of 2016 at Arjasa Pharmacy in Malang. Method This research is a non-experimental research with descriptive research type. The population in this study were all pharmacists managing the Arjasa pharmacy and the sample in this study were 7 pharmacists who were willing to become respondents. The data was collected by using a questionnaire containing 39 statements. The questionnaire was filled in by the respondent, namely the pharmacist who manages the Arjasa Pharmacy in Malang. Resuld Based on the results of the research that has been carried out, Arjasa 1 and 2 Pharmacies are pharmacies owned by their own pharmacists, so that the implementation of pharmaceutical service standards has almost entirely been carried out. Conclusion of this study is that the percentage of compliance with the implementation of pharmaceutical services at Arjasa 1 and 2 Pharmacies with Minister of Health Regulation No. 73 in 2016 amounted to $95.24 \%$ for the management of pharmaceutical preparations and $100 \%$ for clinical pharmacy services.
\end{abstract}

Keywords: Arjasa Pharmacy, Health Ministry Rules of Republic Indonesia number 73 of 2016 Pharmaceutical Service Standard in Pharmacies 


\section{PENDAHULUAN}

Pelayanan kefarmasian adalah suatu pelayanan yang bertanggung jawab langsung kepada pasien yang berhubungan dengan sediaan farmasi yang bertujuan untuk meningkatkan mutu kehidupan pasien (Musdalipah dkk, 2017). Standar pelayanan kefarmasian adalah meliputi standar pengelolaan sediaan farmasi dan pelayanan farmasi klinis dan didukung oleh ketersediaan sumber daya kefarmasian (Kemenkes, 2014).

Menurut Permenkes nomor 73 tahun 2016 apotek adalah sarana pelayanan kefarmasian tempat dilakukan praktik kefarmasian oleh apoteker, sedangkan apoteker adalah sarjana farmasi yang telah lulus sebagai apoteker dan telah mengucapkan sumpah jabatan apoteker. Apotek didirikan sebagai sarana pelayanan kefarmasian yang menyediakan obat maupun alat-alat kesehatan dengan kualitas serta keamanan yang terjamin. Standar pelayanan kefarmasian di apotek merupakan dasar dalam pelayanan apotek dan sebagai tolak ukur yang dipergunakan sebagai pedoman bagi tenaga kefarmasian, dalam menyelenggarakan pelayanan kefarmasian. Dengan demikian pemerintah mengeluarkan peraturan yang berkaitan erat dengan standar pelayanan kefarmasian di apotek yang berlaku di Indonesia saat ini adalah Peraturan Menteri Kesehatan Republik Indonesia Nomor 73 Tahun 2016 tentang standar pelayanan kefarmasian di apotek.

Sampai saat ini masih diragukan seberapa jauh penerapan dari standar pelayanan kefarmasian ini dilakukan di tiap-tiap apotek. Seperti salah satu penelitian di Indonesia mengenai standar pelayanan kefarmasian di apotek yang menjelaskan bahwa pelaksanaan standar pelayanan kefarmasian di apotek di Kabupaten Semarang masih belum optimal karena pengetahuan tentang pelaksanaan standar pelayanan kefarmasian di apotik belum memadai (Cahyono dkk, 2015). Penelitian lain juga dilakukan oleh Sidrotullah dan Radiah (2019) tentang implementasi standar pelayanan kefarmasian di apotek Kota Mataram didapatkan hasil belum sepenuhnya melaksanakan standar pelayanan kefarmasian di apotek. Penelitian yang dilakukan oleh Mongi (2020) juga menunjukkan hasil bahwa penerapan standar pelayanan kefarmasian di Apotek Telemedika Farma 14 Manado belum sepenuhnya dilaksanakan. 
Jurnal Kesehatan Hesti Wira Sakti

ISSN 2302-4283 (print)

ISSN 2580-9571 (online)

Online di https://jurnal.poltekkes-soepraoen.ac.id

DOI: $10.47794 /$ jkhws.v8i2

Apotek Arjasa adalah apotek yang berada di wilayah di Malang dan belum pernah dilakukan penelitian tentang gambaran pelaksanaan standar pelayanan kefarmasian. Keberadaan apotek yang semakin banyak dapat menyebabkan persaingan yang ketat baik dari segi kualitas pelayanan maupun sarana dan prasarana. Selain keberadaan apotek yang semakin banyak, lulusan apoteker di Indonesia juga semakin banyak sehingga ada tuntutan dari masyarakat untuk meningkatkan mutu pelayanan kefarmasian di apotek yang tidak hanya berorientasi kepada obat. Pelayanan yang maksimal dapat dicapai dengan cara apotek wajib menerapkan standar pelayanan kefarmasian dengan mengacu pada Keputusan Menteri Kesehatan Nomor 73 tahun 2016 selama menjalankan praktek kefarmasian.

\section{METODE PENELITIAN}

Penelitian ini menggunakan metode penelitian deskriptif kualitatif dengan pengambilan data menggunakan kuesioner. Kuesioner bersumber pada Permenkes Nomer 73 Tahun 2016. Sampel penelitian ini adalah Apotek Arjasa 1 dan Arjasa 2.

Analisis data dilakukan dengan cara menghitung persentase hasil jawaban dari kuisioner kemudian dideskripsikan tentang

gambaran pelaksanaan pelayanan kefarmasian berdasarkan standare yang berlaku.

Semua data yang terkumpul akan dicatat skornya dan dihitung frekuensinya untuk masing-masing item pertanyaan dan diolah dengan microsft excel dan ditampilkan dalam bentuk tabel. Perhitungan skor tiap kuesioner sebagai berikut :

$\%$ Standar pelayanan kefarmasian =

$\frac{\text { Skor Kuesioner }}{\text { Skor Total }} \times 100 \%$

Tabel 1. Kategori Interval Jawaban (Narimawati, 2007)

\begin{tabular}{ccc}
\hline No & Alternatif Jawaban & $\begin{array}{c}\text { Interval } \\
\text { jawaban (\%) }\end{array}$ \\
\hline 1. & Sangat Baik & $100-84,01 \%$ \\
\hline $\mathbf{2 .}$ & Baik & $84 \%-68,01 \%$ \\
\hline 3. & Cukup Baik & $68 \%-52,01 \%$ \\
\hline $\mathbf{4 .}$ & Kurang Baik & $52 \%-36,01 \%$ \\
\hline $\mathbf{5 .}$ & Tidak Baik & $36 \%-20 \%$ \\
\hline
\end{tabular}

\section{HASIL PENELITIAN}

Penelitian ini dilakukan di Apotek Arjasa 1 dengan alamat Jl. Raya Sengkaling 239A Kecamatan Dau Kota Malang dan di Apotek Arjasa 2 dengan alamat J1. Kertanegara No. 50 Kecamatan Karang Ploso Kota Malang. Karakteristik responden dalam penelitian ini dibagi menjadi lima karakter, yaitu berdasarkan jenis kelamin, usia, status, lama kerja dan kehadiran. Sedangkan karakteristik apotek dalam penelitian ini dibagi menjadi tiga karakter, yaitu frekuensi apotek buka, lama 
Jurnal Kesehatan Hesti Wira Sakti

ISSN 2302-4283 (print)

ISSN 2580-9571 (online)

Online di https://jurnal.poltekkes-soepraoen.ac.id

DOI: $10.47794 /$ jkhws.v8i2

apotek beroperasi memberikan pelayanan,

dan jenis apotek.

Tabel 2. Karakteristik Responden dan Apotek

\begin{tabular}{|c|c|c|c|c|c|}
\hline No & \multicolumn{3}{|c|}{ Variabel } & 1 & 2 \\
\hline 1 & $\begin{array}{l}\text { Jenis } \\
\text { Kelamin }\end{array}$ & $\begin{array}{ll}\text { a. } & \text { Laki-la } \\
\text { b. } & \text { Peremp }\end{array}$ & ki & $\mathrm{b}$ & $\mathrm{a}$ \\
\hline 2 & Usia & $\begin{array}{ll}\text { a. } & 22-30 \mathrm{t} \\
\text { b. } & 31-40 \mathrm{t} \\
\text { c. } & 41-49 \mathrm{t} \\
\text { d. } & >50 \mathrm{th}\end{array}$ & & $\mathrm{d}$ & d \\
\hline 3 & $\begin{array}{l}\text { Lama } \\
\text { Bekerja di } \\
\text { Apotek }\end{array}$ & $\begin{array}{ll}\text { a. } & <5 \text { th } \\
\text { b. } & 5-10 \text { th } \\
\text { c. } & 11-20 \text { t } \\
\text { d. } & >20 \text { th }\end{array}$ & & d & d \\
\hline 4 & $\begin{array}{l}\text { Status } \\
\text { Apoteker }\end{array}$ & $\begin{array}{ll}\text { a. } & \text { APA } \\
\text { b. } & \text { Apotek } \\
& \text { Pengga } \\
\text { c. } & \text { PSA } \\
\text { d. } & \text { Apotek }\end{array}$ & $\begin{array}{l}\text { er } \\
\text { nti }\end{array}$ & d & d \\
\hline 5 & Kehadiran & $\begin{array}{ll}\text { a. } & \text { Selama } \\
& \text { apotek } \\
\text { b. } & 1-7 \text { jam } \\
\text { c. } & \text { 2-3 } \\
& \text { hari/mi } \\
\text { d. } & \text { 2-3 har } \\
\end{array}$ & $\begin{array}{l}\text { jam } \\
\text { buka } \\
\text { //hari } \\
\text { nggu } \\
\text { i/bulan }\end{array}$ & $\mathrm{d}$ & d \\
\hline 6 & $\begin{array}{l}\text { Frekuensi } \\
\text { apotek } \\
\text { buka }\end{array}$ & $\begin{array}{ll}\text { a. } & \text { Kurang } \\
& \text { jam/har } \\
\text { b. } & 12-18 \mathrm{j} \\
\text { c. } & 19-23 \mathrm{j} \\
\text { d. } & 24 \mathrm{jam}\end{array}$ & $\begin{array}{l}\text { dari } 12 \\
\text { ai } \\
\text { am/hari } \\
\text { am/hari } \\
\text { /hari }\end{array}$ & $\mathrm{b}$ & b \\
\hline 7 & $\begin{array}{l}\text { Lama } \\
\text { Apotek } \\
\text { beroperasi } \\
\text { memberik } \\
\text { an } \\
\text { pelayanan }\end{array}$ & $\begin{array}{ll}\text { a. } & 1-5 \text { th } \\
\text { b. } & 6-10 \text { th } \\
\text { c. } & 11-15 \text { t } \\
\text { d. } & 15 \text { th }\end{array}$ & h atas & $\mathrm{d}$ & $\mathrm{d}$ \\
\hline 8 & $\begin{array}{l}\text { Jenis } \\
\text { Apotek }\end{array}$ & $\begin{array}{ll}\text { a. } & \text { BUMN } \\
& \text { sama } \\
& \text { Dokter } \\
& \text { BPJS } \\
\text { b. } & \text { Swasta } \\
& \text { tidak } \\
\text { sama } & \text { BPJS } \\
& \text { Dokter } \\
\text { c. } & \text { Swasta } \\
& \text { bekerja } \\
\text { dengan }\end{array}$ & $\begin{array}{r}\text { bekerja } \\
\text { dengan } \\
\text { dan } \\
\text { yang } \\
\text { bekerja } \\
\text { dengan } \\
\text { dan } \\
\text { yang } \\
\text { sama } \\
\text { dokter }\end{array}$ & $\mathrm{a}$ & $\mathrm{b}$ \\
\hline
\end{tabular}

Tabel 3. Pengelolaan Sediaan Farmasi

Alat Kesehatan dan BMHP

\begin{tabular}{|c|c|c|}
\hline No & Pernyataan & $\begin{array}{c}\text { Persentase } \\
\text { Pelaksanaan } \\
\text { berdasarkan } \\
\text { Standar }(\%) \\
\end{array}$ \\
\hline 1 & $\begin{array}{l}\text { Perencanaan sediaan } \\
\text { farmasi, alat kesehatan } \\
\text { dan BMHP }\end{array}$ & 100 \\
\hline 2 & $\begin{array}{l}\text { Pengadaan sediaan } \\
\text { farmasi, alat kesehatan } \\
\text { dan BMHP }\end{array}$ & 100 \\
\hline 3 & $\begin{array}{l}\text { Penerimaan sediaan } \\
\text { farmasi, alat kesehatan } \\
\text { dan BMHP }\end{array}$ & 100 \\
\hline 4 & $\begin{array}{l}\text { Penyimpanan sediaan } \\
\text { farmasi, alat kesehatan } \\
\text { dan BMHP }\end{array}$ & 100 \\
\hline 5 & $\begin{array}{lr}\text { Pemusnahan } & \text { dan } \\
\text { penarikan } & \text { sediaan } \\
\text { farmasi } & \\
\end{array}$ & 100 \\
\hline 6 & $\begin{array}{l}\text { Pengendalian sediaan } \\
\text { farmasi, alat kesehatan } \\
\text { dan BMHP }\end{array}$ & 100 \\
\hline 7 & $\begin{array}{lr}\text { Pencatatan } & \text { dan } \\
\text { pelaporan } & \text { sediaan } \\
\text { farmasi, alat } & \text { kesehatan } \\
\text { dan BMHP } & \\
\end{array}$ & 66.67 \\
\hline
\end{tabular}

\section{Tabel 4. Pelaksanaan Pelayanan}

\section{Farmasi Klinik}

\begin{tabular}{llc}
\hline No & Pernyataan & $\begin{array}{c}\text { Persentase } \\
\text { Pelaksanaan } \\
\text { berdasarkan } \\
\text { Standar (\%) }\end{array}$ \\
\hline 1 & Pengkajian dan pelayanan & 100 \\
& resep & \\
\hline 2 & Dispensing & 100 \\
\hline 3 & Pelayanan informasi obat & 100 \\
\hline 4 & $\begin{array}{l}\text { Pelayanan farmasi klinis } \\
\text { konseling }\end{array}$ & 100 \\
\hline 5 & Pemantauan Terapi Obat & 100 \\
\hline 6 & $\begin{array}{l}\text { Monitoring efek samping } \\
\text { obat }\end{array}$ & 100 \\
\hline 7 & $\begin{array}{l}\text { Pelayanan kefarmasian di } \\
\text { rumah }\end{array}$ & 100 \\
\hline
\end{tabular}

Ketetangan : (1 dan 2 adalah Apotek Arjasa 1 dan Apotek Arjasa 2)

Kolom keempat diisi berdasarkan pilihan dari kolom 3 
Jurnal Kesehatan Hesti Wira Sakti

ISSN 2302-4283 (print)

ISSN 2580-9571 (online)

Online di https://jurnal.poltekkes-soepraoen.ac.id

DOI: $10.47794 /$ jkhws.v8i2

PEMBAHASAN

\section{Karakteristik Responden dan Apotek}

Berdasarkan hasil penelitian diperoleh hasil bahwa karakteristik responden berdasarkan jenis kelamin adalah laki-laki dan perempuan. Menurut Robbins (2003) bahwa tidak ada perbedaan yang bermakna antara laki-laki dan perempuan dalam kemampuan memecahkan masalah dalam suatu pekerjaan. Sedangkan berdasarkan usia apotek dikelola oleh APA dengan usia lebih dari 50 tahun yang mana di usia tersebut masih tergolong usia produktif sehingga diharapkan responden masih bisa dengan jelas untuk memahami kuisioner yang diberikan dan masih maksimal dalam memberikan pelayanan kefarmasian. Apotek Arjasa 1 dan 2 dikelola oleh APA yang sekaligus berperan sebagai PSA, sehingga berpeluang besar apotek untuk dapat memberikan pelayanan kefarmasian yang lebih baik dibandingkan dengan apotek yang kepemilikannya bukan APA (Novianita, 2016). Karakteristik responden dan Apotek lainnya sudah sesuai dengan standar yang berlaku.

\section{Karakteristik Standar Pelayanan Kefarmasian}

Standar pelayanan kefarmasian di apotek terdiri dari 2 kegiatan yaitu, pengelolaan sediaan kefarmasian, alat kesehatan dan BMHP dan pelayanan farmasi klinis. Berdasarkan hasil penelitian yang Jurnal Kesehatan Hesti Wira Sakti

dilakukan diperoleh hasil bahwa untuk pelaksanaan pengelolaan sediaan farmasi, alat kesehatan dan BMHP di Apotek Arjasa 1 dan 2 diperoleh persentase 95,24\% yang artinya sudah dilaksanakan dengan sangat baik. Adapun kekurangan dalam pengelolaan sediaan farmasi di apotek ini adalah untuk pencatatan masih belum menggunakan pencatatan melalui komputer. Sementara untuk pelayanan farmasi klinis Apotek Arjasa 1 dan 2 memperoleh persentase sebesar $100 \%$ yang artinya semua kegiatan pelayanan farmasi klinis sudah dilakukan sesuai dengan Standar Pelayanan Kefarmasian berdasarkan Permenkes No. 73 tahun 2016.

\section{KESIMPULAN}

Berdasarkan hasil penelitian standar pelayanan kefarmasian di Apotek Arjasa 1 dan 2 Malang dapat disimpulkan bahwa kesesuaian pelaksanaan pelayanan kefarmasian dengan Permenkes Nomor 73 tahun 2016 adalah sebesar 95,24\% untuk bidang pengelolaan sediaan kefarmasian, $100 \%$ untuk pelayanan farmasi klinik yang berarti pelayanan kefarmasian sudah dilaksanakan dengan sangat baik.

\section{DAFTAR PUSTAKA}

Cahyono, L.T., Sudiro dan Suparwan A. 2015. Pelaksanaan Standar Pelayanan Kefarmasian Pada Vol 8 no 2 tahun 2020 
Online di https://jurnal.poltekkes-soepraoen.ac.id

DOI: $10.47794 / \mathrm{jkhws.v8i2}$

Apotek Di Kabupaten Semarang. Jurnal Manajemen Kesehatan Indonesia.

Kemenkes. 2014. Peraturan Menteri Kesehatan Republik Indonesia Nomor 35 Tahun 2014. Jakarta.

Mongi, D., Pareta, D., Maarisit, W., \& kanter, J. 2020. Evaluasi Pelaksanaan Pelayanan Kefarmasian Di Apotek Telemedika Farma 14 Manado. Universitas Kristen Indonesia Tomobon.

Musdalipah, Muh. Syaiful Saehu, Asmiati. 2017. Analisis Pelayanan Kefarmasian Di Puskesmas Tosiba Kabupaten Kolaka. Akademi Farmasi Bina Husada Kendari. Vol. 6 No.2.

Narimawati, U. 2007. Riset Manajemen Sumber Daya Manusia. Agung Media. Jakarta.
Novianita, Made, I Nyoman Sutarsa, I Nyoman Adiputra. 2016. Faktor Yang Berhubungan dengan Kualitas Pelayanan Kefarmasian di Kota Denpasar. Public health and Preventive Medicine Archive, Vol. 4, No. 1 : 42-47

Permenkes. 2016. Peraturan Menteri Kesehatan Republik Indonesia Nomor 73 Tahun 2016 tentang Standar Pelayanan Kefarmasian di Apotek. Jakarta: Menteri Kesehatan Republik Indonesia.

Robbins, Stephen P. 2003. Perilaku Organisasi. PT. Indeks Kelompok Gramedia. Jakarta.

Sidrotulloh, M., Nur Radiah. 2019. Implementasi Standar Pelayanan Kefarmasian Di Apotek. Universitas Nahdlatul Wathan, Mataram Indonesia. Vol. 3 No. 1. 